lao phổi có kháng Rifampicin có mức độ AFB dương tính $1+$ là $20,83 \%$ và ở nhóm bệnh nhân không kháng Rifampicin là 79,17\%. AFB dương tính 2+ ở nhóm lao phổi có kháng Rifampicin là $40 \%$ ở nhóm lao phổi không kháng Rifampicin là $60 \%$. Mức AFB dương tính 3+ ở nhóm lao phổi có kháng Rifampicin là 33,33\% và ở nhóm lao phổi không kháng Rifampicin là $66,67 \%$. Như vậy kết quả của tác giả cho thấy ở nhóm bênh nhân có kháng Rifampicin có số lương vi khuẩn trong đờm ở các mức độ 1+, 2+, 3+ đều thấp hơn nhóm lao phổi không kháng Rifampicin. Sự khác biệt này có thể do cõ̃ mẫu nghiên cứu khác nhau.

\section{KẾT LUẬN}

Lao đa kháng thuốc ngày càng tăng, mối tương quan lâm sàng, cận lâm sàng với đặc tính kháng thuốc có rất nhiều ý nghĩa cho việc điều trị bệnh.

\section{TÀI LIẸU THAM KHẢO}

1. World Health Organization (2018) Global Tuberculosis report. WHO,
apps.who.int/iris/handle/10665/274453,8-37.
2. Girum T, Muktar E, Lentiro K (2018), Epidemiology of multidrug-resistant tuberculosis (MDR-TB) in Ethiopia: a systematic review and meta-analysis of the prevalence, determinants and treatment outcome".Trop Dis Travel Med Vaccines.4:5. doi: 10.1186/s40794-018-0065-5.

3. Adigun $\mathbf{R}$, Singh $\mathbf{R}(\mathbf{2 0 1 9})$, "Tuberculosis", StatPearls [Internet]. Treasure Island (FL): StatPearls Publishing; 2019 Feb 6.

4. Jamshid Gadoev, Damin Asadov, Anthony D. Harries Recurrent tuberculosis and associated factors: A five - year countrywide study in Uzbekistan (2017), "", PLoS One. 2017; 12(5): e0176473. 10.1371/journal.pone.0176473.

5. Nguyễn Thị Hậu (2015), "Nghiên cứu lâm sàng, cận lâm sàng, tỷ lệ kháng thuốc và kết quả điều trị tẩn công ở bệnh nhân lao phổi tái phát". Luân văn Thạc sỹ, Học viện Quân y, Hà Nội 67tr.

6. Jacobs MG, Pinto Junior VL (2020), "Characterization of drug-resistanttuberculosis in Brazil, 2014", Epidemiol Serv Saude. 2020 Feb 3;28(3):e2018294. doi: 10.5123/S1679

7. Nguyến Văn Thái (2019), "Nghiên cứ tính kháng Rifampicin và môi liên quan giữa một số đăc điểm lâm sàng cận lâm sàng với tính kháng thuốc ở bệnh nhân lao phổi tái phát, Luận văn chuyên khoa 2, Học viện Quân y, Hà Nội72tr.

\title{
MộT SỐ YẾU TỐ LIÊN QUAN ĐẾN KẾT QUẢ ĐIỀU TRỊ HORMON TÁI Tổ HỢP Ở TRẺ THIẾU HỤT HORMON TĂNG TRƯỞNG
}

\section{TÓM TẮT}

Thiếu hụt hormon tăng trưởng là tình trạng tuyến yên không sản xuất đủ hormon tăng trưởng dấn đến tình trạng lùn ở trẻ em. Tỷ lệ mới mắc dao động $1 / 3500-1 / 4000$. Mục tiêu: Nhận xét một số yếu tố liên quan đến kết quả điều trị hormon tái tổ hợp ở trẻ thiếu hụt hormon tăng trưởng. Đối tượng và phương pháp: 159 bệnh nhân được chẩn đoán và điều trị thiếu hụt hormon tăng trưởng tại Bệnh viện Nhi Trung ương từ tháng 01 năm 2010 đến tháng 06 năm 2019. Nghiên cứu một loạt ca bệnh, đối chứng trước và sau điều trị. Kết quả: trong số 159 bệnh nhân thì nhóm bệnh nhân có nồng độ $\mathrm{GH}$ đỉnh test kích thích $\leq 5 \mathrm{ng} / \mathrm{ml}$ có mối tương quan tuyến tính giữa tốc độ tăng trưởng chiêu $\mathrm{cao}(\mathrm{cm})$ trong năm đầu với nồng độ $\mathrm{GH}$ đỉnh, nồng độ $\mathrm{GH}$ đỉnh càng thấp, tốc đô̂ tăng trưởng càng cao; ngoài ra tuổi bắt đầu điều trị, tuổi xương thời điểm bắt đầu điều trị đều có mối tương quan tuyến tính với tốc độ tăng trưởng chiều cao (SDS, cm) trong năm đâu, điêu trị càng

*Bệnh viện Nhi Trung Uơng

Chịu trách nhiệm chính: Vũ Chí Dũng

Email: dungvu@nch.org.vn

Ngày nhận bài: 28.12.2020

Ngày phản biện khoa họ: 25.01.2021

Ngày duyệt bài: 2.2.2021

\section{Vũ Chí Dũng*, Nguyễn Thị Hằng*}

sớm, tuổi xương càng thấp thì tốc độ tăng trưởng chiều cao năm đâuu càng cao. Kết luận: Bệnh nhân được chẩn đoán và điều trị thiếu hụt hormon tăng trưởng sớm, tuổi xương và nồng độ GH đỉnh test kích thích thấp có đáp ứng tốt hơn với liệu pháp hormon tái tổ hợp thay thế.

Tư khóa: Thiếu hụt hormon tăng trưởng, hormon tăng trưởng tái tổ hợp, lùn ở trẻ em.

\section{SUMMARY}

\section{FACTORS AFFECTING HEIGHT VELOCITY RESPONSE IN rhGH- TREATED CHILDREN WITH GROWTH HORMONE DEFICIENCY}

Growth hormone deficiency is a condition that occurs when the pituitary gland does not produce enough growth hormone. This is the most common endocrine cause in short status which incidence is between $1 / 3500-1 / 4000$. Objective: to study factors affecting the height velocity response in $\mathrm{rhGH}$ treated children with growth hormone deficiency. Patiens and Method: A case series study and comparing before and after treatment with rhGH, 159 patients with growth hormone deficiency was evaluated at National Children's Hospital from 1/2010 to 6/2019. Results: A significantly negative correlation was seen between first year change in height (cm, SDS) and bone age, chronological age at initiation of treatmen while a significantly negative 
correlation was seen between first year change in height $\mathrm{cm}$ and peak serum $\mathrm{GH}$ level.

Keywords: recombinant growth hormone, growth hormone deficiency, Short stature in Children

\section{I. ĐẶT VẤN ĐỀ}

Thiếu hụt hormon tăng trưởng là tình trạng xảy ra khi tuyến yên không sản xuất đủ hormon tăng trưởng. Thiếu hụt này có thể là đơn thuần hoặc phối hợp. Tỷ lệ mắc thiếu hụt hormon tăng trưởng dao động ở các nước khác nhau trong các báo cáo, trung bình từ 1/3500 - 1/4000 [1]. Phần lớn trẻ bị thiếu hụt hormon tăng tưởng có chiều cao thấp. Nếu không được điều trị, chiều cao khi trưởng thành ở trẻ nam chỉ đạt 134 $146 \mathrm{~cm}$, ở trẻ nữ là $128-134 \mathrm{~cm}$ [2]. Chiều cao thấp làm giảm chất lượng cuộc sống, tăng nguy cơ mắc các bệnh chuyển hóa khác. Tuy nhiên chẩn đoán nguyên nhân bệnh gặp nhiều khó khăn, điều trị lâu dài, tốn kém và đòi hỏi tuân thủ điều trị nghiêm ngặt. Ở Việt Nam, đã có một số nghiên cứu về thiếu hụt hormon tăng trưởng. Tuy nhiên các nghiên cứu mới đề cập đến đặc điểm lâm sàng và điều trị trên một số ít bệnh nhân, do trong những năm trước đầy thuốc đắt, chưa được bảo hiểm y tế chi trả, số lượng bệnh nhân được điều trị ít, điều trị không liên tục, thời gian điều trị ngắn, chưa tìm được các yếu tố ảnh hưởng kết quả điêu trị nhằm mục đích theo dõi và tiên lượng. Vì vậy, nghiên cứu được được tiến hành với mục tiêu: nhận xét một số yếu tố liên quan đến kết quả điều trị hormon tái tổ hợp ở trẻ thiếu hụt hormon tăng trưởng.

\section{II. ĐỐI TƯợNG VÀ PHƯƠNG PHÁP NGHIÊN CỨU}

Đối tượng nghiên cứu: Tất cả các bệnh nhân được chẩn đoán thiếu hụt hormon tằng trưởng và được theo dõi điều trị tại Khoa Nội tiết - Chuyển hóa - Di truyền Bệnh viện Nhi trung ương từ tháng 1 năm 2010 đến tháng 6 năm 2019, có thời gian điêu trị từ 12 tháng trở lên.

Phương pháp nghiên cứu: Nghiên cứu một loạt ca bệnh, đối chiếu trước và sau điều trị.

Phân tích và xử lí số liệu: Số liệu được xử lý theo thuật toán thống kê trên máy tính bằng phần mềm Excell và SPSS 20.

Tiêu chuẩn chẩn đoán: Theo hướng dẫn của Hội các nhà nội tiết lâm sàng Hoa Kỳ năm 2003 [3] và Hội nội tiết nhi khoa Hoa Kỳ [4]:

- Tré có chiêu cao <-2SD so với quần thể cùng tuổi, cùng giới (đã loại trừ những nguyên nhân gây chậm tăng trưởng khác: suy giáp trạng bẩm sinh, bệnh mạn tính, hội chứng Turner).

- Chiều cao dự báo dưới -1.5SD so với chiều cao trung bình của bố mẹ.
- Chiêu cao dưới - 2SD và tốc độ tăng trưởng chiều cao dưới -1SD trong vòng 1 năm hoặc độ lệch chuẩn chiều cao giảm trên 0,5 SD trong vong 1 năm ở trẻ trên 2 tuổi.

- Trong trường hợp không có tầm vóc thấp, tốc độ tăng trưởng chiêu cao dưới - 2SD trong vòng 1 năm hoặc dưới $-1.5 \mathrm{SD}$ trong vòng 2 năm.

- Dâu hiệu lâm sàng của tổn thương nội sọ, thiếu hụt hormon khác của tuyến yên: hạ glucose máu, vàng da kéo dài, dương vật nhỏ ở trẻ sơ sinh.

- Nghiệm pháp kích thích $\mathrm{GH}$ với nồng độ $\mathrm{GH}$ đỉnh trong huyết tương $<10 \mathrm{ng} / \mathrm{ml}$ (nghiệm pháp kích thích với Clonidine, Glucagon hoặc Insulin).

- Nồng đô IGF1 và/hoặc IGFBP3 dưới -2SD so với quần thể bình thường cùng tuổi và giới.

- Xquang tuổi xương: tuổi xương chậm hơn so với tuổi thực.

\section{KẾT QUẢ NGHIÊN CỨU}

Trong số các bệnh nhân nghiên cứu có 18 bệnh nhân có nồng độ $\mathrm{GH}$ đỉnh sau test kích thích $\leq 5 \mathrm{ng} / \mathrm{ml}$.

Bảng 3.1. Tương quan giữa nồng độ $G H$ đỉnh test kích thích $\leq 5 \mathrm{ng} / \mathrm{ml}$ và hiệu quả điều trị

\begin{tabular}{|c|c|c|c|}
\hline \multirow{2}{*}{ GH } & \multicolumn{3}{|c|}{$\begin{array}{c}\text { Nông độ GH đỉnh trong test } \\
\text { kích thích } \leq \mathbf{5} \mathbf{~ n g / m I}\end{array}$} \\
\cline { 2 - 4 } Chiêu cao & $\mathbf{n}$ & $\mathbf{r}$ & $\mathbf{p}$ \\
\hline $\begin{array}{c}\text { Tăng chiêu cao } \\
\text { trong năm } 1\end{array}$ & 18 & $-0,493 * *$ & $\mathbf{0 , 0 3 8}$ \\
\hline $\begin{array}{c}\text { Tăng SD chiều } \\
\text { cao trong năm } 1\end{array}$ & 18 & $-0,307^{* *}$ & 0,216 \\
\hline
\end{tabular}

**Hệ số tương quan $r$ Spearman cho 2 biến không tuân theo quy luật chuẩn

Nhận xét: Đối với nhóm bệnh nhân có nồng độ $\mathrm{GH}$ đỉnh $\leq 5 \mathrm{ng} / \mathrm{ml}$, có mối tương quan tuyến tính giữa tốc độ tăng trưởng chiều cao trong năm đâu với nồng độ $\mathrm{GH}$ đỉnh. Khi nồng độ GH đỉnh càng thấp thì chiều cao cải thiện càng tốt với $p<0,05$.

Bảng 3.2. Tương quan giứa tuổi bắt đầu điều trị và hiệu quả điều trị

\begin{tabular}{|c|c|c|c|}
\hline \multirow{2}{*}{ Chiều cao Yếu tố } & \multicolumn{3}{|c|}{ Tuổi bắt đâu điêu trị } \\
\cline { 2 - 4 } & $\mathbf{n}$ & $\mathbf{r}$ & $\mathbf{p}$ \\
\hline $\begin{array}{c}\text { Tăng chiều cao } \\
\text { trong năm 1 }\end{array}$ & 159 & - & $0,159 * *$ \\
\hline $\begin{array}{c}\text { Tăng SD chiều } \\
\text { cao trong năm 1 }\end{array}$ & 159 & $\begin{array}{c}- \\
0,382 * *\end{array}$ & $\mathbf{0 , 0 0 0}$ \\
\hline
\end{tabular}

*Hệ số tương quan $r$ Pearson cho 2 biến tuân theo quy luật chuẩn

**Hệ số tương quan $r$ Spearman cho 2 biến không tuân theo quy luật chuẩn

Nhận xét: Có mối tương quan tuyến tính 
giữa tuổi bắt đầu điều trị và tốc đô tăng trưởng chiều cao trong năm đầu, tuổi bắt đâuu điều trị càng thấp, tốc tộ tăng trưởng chiều cao trong năm đâu càng cao.

Bảng 3.3. Tương quan giữa tuổi xương thời điểm bắt đầu điều trị và hiệu quả điều trị

\begin{tabular}{|c|c|c|c|}
\hline \multirow{2}{*}{ Chî̀u cấu tố } & \multicolumn{3}{|c|}{ Tuối xương bắt đâu điều trị } \\
\cline { 2 - 4 } & $\mathbf{n}$ & $\mathbf{r}$ & $\mathbf{p}$ \\
\hline $\begin{array}{c}\text { Tăng chiều cao } \\
\text { trong năm 1 }\end{array}$ & 138 & $-0,226^{* *}$ & $\mathbf{0 , 0 0 8}$ \\
\hline
\end{tabular}

\begin{tabular}{|c|c|c|c|}
\hline $\begin{array}{c}\text { Tăng SD chiêu } \\
\text { cao trong năm } 1\end{array}$ & 138 & $-0,418^{* *}$ & $\mathbf{0 , 0 0 0}$ \\
\hline
\end{tabular}

*Hệ số tương quan $r$ Pearson cho 2 biến tuân theo quy luật chuẩn

**Hế số tương quan $r$ Spearman cho 2 biến không tuân theo quy luật chuẩn

Nhận xét: Có mối tương quan tuyến tính giữa tuổi xương bắt đầu điều trị và tốc độ tăng chiều cao trong năm đầu, tuổi xương bắt đầu điều trị càng thấp, tốc tộ tăng chiều cao trong năm đầu càng cao.

Bảng 3.4. Các yếu tố dự đoán ảnh hưởng đến tốc độ tăng trưởng chiều cao trong năm đâu

\begin{tabular}{|c|c|c|c|c|}
\hline \multirow{2}{*}{ Biến phụ thuộc } & \multicolumn{2}{|c|}{$\begin{array}{c}\text { Tăng chî̂u cao năm độc lập } \\
\text { đầu }\end{array}$} & \multicolumn{2}{|c|}{$\begin{array}{c}\text { Tăng SD chiều cao } \\
\text { nắm đâu (SD) }\end{array}$} \\
\cline { 2 - 5 } & $\mathbf{B}$ & $\mathbf{p}$ & $\mathbf{B}$ & $\mathbf{p}$ \\
\hline Nồng độ GH đỉnh thời điểm chẩn đoán & $-0,243$ & 0,157 & $-0,057$ & 0,734 \\
\hline Tuối bắt đầu điều trị & $-0,229$ & 0,407 & 0,003 & 0,992 \\
\hline Tuối xương lúc bắt đầu điều trị & $-0,317$ & 0,233 & $-0,524$ & $\mathbf{0 , 0 5}$ \\
\hline
\end{tabular}

Sử dụng thuật toán phân tích hồi quy đa biến

Nhận xét: Không có mối tương quan nào giữa nồng độ GH đỉnh thời điểm chẩn đoán, tuổi bắt đầu điểu trị với tốc độ tăng chiều cao, tốc độ tăng SDS chiều cao trong năm đầu. Tuổi xương lúc bắt đầu điều trị có xu hướng có mối tương quan với tăng SDS chiều cao năm đầu $(p=0,05)$.

\section{BÀN LUÂ̂N}

Trong nghiên cứu của chúng tôi, có tương quan tuyến tính nghịch biến giữa tuổi bắt đầu điêu trị và tốc độ tắng chiều cao theo $\mathrm{cm}$ và theo SD năm đầu tiên $(p<0,05)$ khi so sánh tương quan đơn biến. Kết quả này phù hợp với nhiều nghiên cứu trên thế giới. Nghiên cứu đa trung tâm đánh giá hiệu quả và an toàn lâu dài của GH tái tổ hợp được thực hiện bởi Polak và cộng sự năm 2017 đánh giá trên 172 trẻ thiếu hụt hormon tăng trưởng. Bệnh nhân tham gia nghiên cứu được phân vào các nhóm phụ thuộc tuổi bắt đầu điều trị: sớm (nữ $<8$ tuổi, nam $<9$ tuổi), trung bình (nữ 8-10 tuổi, nam 9-11 tuổi) và muô̂n (nữ > 10 tuổi, nam > 11 tuổi). Kết quả cho thấy, tốc độ tăng trưởng chiều cao tuổi trưởng thành của nhóm điều trị sớm cao hơn hai nhóm còn lại $(-1,0 \pm 1,2$ SD so với $-1,5 \pm 0,9$ $\mathrm{SD}$ của nhóm trung bình và $-1,3 \pm 1,1 \mathrm{SD}$ ơ nhóm muộn). Như vậy điều trị càng sớm, tốc độ tăng trưởing chiều cao tuổi trưởng thành càng gần về mức 0 SD [5].

Trong nghiên cứu của chúng tôi, tuổi xương lúc bắt đâu điều trị có mối tương quan tuyến tính với tốc độ tăng chiều cao, tốc độ tăng tốc độ tăng trưởng chiêu cao trong năm đầu, kết quả này phù hợp với nhiều nghiên cứu trên thế giới. Nghiên cứu của tác giả Jae và cộng sự tại Hàn Quốc công bố năm 2019, nghiên cứu đánh giá 78 bênh nhân thiếu hụt hormon tăng trưởng vô căn được điều trị hormon thay thế trong vòng
3 năm. Kết quả nghiên cứu thấy rằng, trước điều trị tuổi xương chậm so với tuổi thực 2,04 1,25 năm, sau 3 năm điều trị tuổi xương tăng trung bình $3,88 \pm 1,36$ tuổi và hiệu số giữa tuổi xương và tuối thực giảm còn $-0,98 \pm 1,23$ năm (có sự khác biệt với hiệu số trước khi điều trị $p=$ $0,009)$. Trong các yếu tố ảnh hưởng đến sự thay đổi tuổi xương trong quá trình điều trị, nghiên cứu chỉ ra tuổi xương lúc bắt đầu điêuu tri (hiệu số tuổi xương và tuổi thực lúc bắt đầu điều trị) có mối tương quan tuyến tính với tiến triển tuổi xương trong những năm sau đó, có ý nghĩa trong đánh giá hiệu quả điều trị [6].

Trong nghiên cứu này, test kích thích $\mathrm{GH}$ bằng glucagon được thực hiện. Trong 2 nhóm, nhóm $\mathrm{GH}$ đỉnh $\leq 5 \mathrm{ng} / \mathrm{ml}$, có mối tương quan tuyến tính giữa nồng độ $\mathrm{GH}$ đỉnh và tốc độ tăng chiêu cao sau năm đâu điều trị. Từ những năm 1960, nồng đô $\mathrm{GH}$ đỉnh cao nhất sau test kích thích $<5 \mathrm{ng} / \mathrm{ml}$ được sử dụng để chẩn đoán thiếu hụt hormon tăng trưởng. Đây được đánh giá là ngưỡng (cut-off) tốt để xác định thiếu hụt hormon tăng trưởng [7]. Nghiên cứu của Straetemans và cộng sự năm 2018 thực hiện trên 121 trẻ thiếu hụt hormon tăng trưởng. Trẻ có tăng trưởng chiêu cao chậm $-3,2$ SD tại thời điểm chẩn đoán và được chia vào 2 nhóm: nhóm thiếu hụt hoàn toàn ( $\mathrm{GH}$ đỉnh $<5 \mathrm{ng} / \mathrm{ml}$ ) và nhóm thiếu hụt 1 phần $(5 \mathrm{ng} / \mathrm{ml} \leq \mathrm{GH}$ đỉnh $<10 \mathrm{ng} / \mathrm{ml}$ ), cả 2 nhóm được điêuu trị với liều $0,0269 \mathrm{mg} / \mathrm{kg} / \mathrm{ngày}$ trong năm đầu tiên. Kết quả 
đánh giá sau 12 tháng cho thây nhóm bệnh nhân thiếu hụt hormon hoàn toàn có tốc độ tắng chiều cao và tăng SDS chiều cao tốt hơn so với nhóm thiếu hự 1 phần (tăng chiều cao: $10,1 \pm 2,8 \mathrm{~cm}$ với $8,4 \pm 1,9 \mathrm{~cm}, \mathrm{p}<0,001$; tốc độ tăng trưởng chiều cao theo SD: $0,97 \pm 0,65 \mathrm{SD}$ và̀ $0,62 \pm 0,42 \mathrm{SD}, \mathrm{p}=0,001)[8]$.

\section{KẾT LUÂ̂N}

Tuổi bắt đầu điều trị, tuổi xương thời điểm bắt đầu điều trị và nồng độ $\mathrm{GH}$ đỉnh trong test kích thích có liên quan tới kết quả điều trị. Điều tri càng sớm, tuổi xương thời điểm bắt đầu điều điều trị và nồng độ $\mathrm{GH}$ đỉnh càng thấp, tốc độ tăng trưởng chiều cao trong năm đầu càng cao.

\section{TÀI LIÊU THAM KHẢO}

1. Dattani M. and Preece M. (2004). Growth hormone deficiency and related disorders: insights into causation, diagnosis, and treatment. Lancet Lond Engl, 363(9425), 1977-1987.

2. Takeda A., Cooper K., Bird A. et al. (2010). Recombinant human growth hormone for the treatment of growth disorders in children: a systematic review and economic evaluation. Health Technol Assess Winch Engl, 14(42), 1-209, iii-iv.

3. Gharib H., Cook D.M., Saenger P.H., et al. (2003). American Association of Clinical Endocrinologists medical guidelines for clinical practice for growth hormone use in adults and children--2003 update. Endocr Pract Off J Am Coll Endocrinol Am Assoc Clin Endocrinol, 9(1), 64-76.

4. Grimberg A., DiVall S.A., Polychronakos $C_{\text {, }}$ et al . (2016). Guidelines for Growth Hormone and Insulin-Like Growth Factor-I Treatment in Children and Adolescents: Growth Hormone Deficiency, Idiopathic Short Stature, and Primary Insulin-Like Growth Factor-I Deficiency. Horm Res Paediatr, 86(6), 361-397.

5. Polak M., Blair J., Kotnik P, et al. (2017) Early growth hormone treatment start in childhood growth hormone deficiency improves near adult

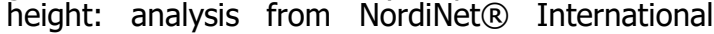
Outcome Study. Eur J Endocrinol, 177(5), 421-429.

6. Kang MJ., Kim EY., Shim YS., et al. (2019). Factors affecting bone age maturation during 3 years of growth hormone treatment in patients with idiopathic growth hormone deficiency and idiopathic short stature: Analysis of data from the LG growth study. Medicine (Baltimore), 98(14), $962-972$.

7. Kaplan S.L., Abrams C.A., Bell J.J, et al. (1968). Growth and growth hormone. I. Changes in serum level of growth hormone following hypoglycemia in 134 children with growth retardation. Pediatr Res, 2(1), 43-63.

8. Straetemans S., Thomas M., Craen $M$, et al. (2018). Poor growth response during the first year of growth hormone treatment in short prepubertal children with growth hormone deficiency and born small for gestational age: a comparison of different criteria. Int J Pediatr Endocrinol, 2018, 9 - 17.

\section{HIÊUU QUẢ ÁP DƯNG THỬ NGHIỆM Bộ CÔNG CỤ GIÁM SÁT CHỦ ĐộNG CHẤT THẢI Y TẾ TẠI BẾNH VIỂN ĐA KHOA KHU VỰC PHÚC YÊN VÀ BỆNH VIÊ̂N ĐA KHOA THANH HÓA NĂM 2017}

\section{Đàm Thương Thương ${ }^{1}$, Nguyễn Thanh Hà ${ }^{2}$ Trần Văn Tuấn ${ }^{3}$}

\section{TÓM TẮT}

Mục tiêu: Đánh giá được hiệu quả áp dung bô công cụ giám sát chủ động chất thải y tễ đối với công tác phẩn loại, thu gom, vận chuyển chất thải rắn tại BVĐK khu vực Phúc Yên và BVĐK tỉnh Thanh Hóa, năm 20217. Phương pháp: Nghiên cứu can thiệp đánh giá trước sau không có nhóm đối chứng, tại 33 khoa của 2 bệnh viện nghiên cứu. Kết quả: Tỷ lệ đạt các tiêu chí đánh giá về dụng cụ, thiết bị lưu chứa chất thải y tế, phân loại, thu gom và vận chuyển chất thải y tế theo từng ngày đều tăng với đa số các tiêu

\footnotetext{
${ }^{1}$ Viện Sức khỏe nghề nghiệp và môi trường-BYT ${ }^{2}$ Cưc Quản lý Môi trường Ỳ tế-BYT

${ }^{3}$ Học viện Quân Y.

Chịu trách nhiệm chính: Đàm Thương Thương

Email: damthuongthuong.nioeh@gmail.com

Ngày nhận bài: 21.12.2020

Ngày phản biện khoa học: 22.01.2021

Ngày duyệt bài: 2.2 .2021
}

chí đạt trên $90 \%$ sau 4 tuân thử nghiêm. Kết luân: Bộ công cụ giám sát chủ động chất thải y tế có hiệu quả trong công tác phân loại, thu gom và vận chuyển chất thải y tế tai hai bệnh viện được thử nghiệm.

Tư khoá: chất thải y tế, giám sát chủ động, quản lý môi trường y tế

\section{SUMMARY}

\section{EFECTIVE OF APPLICATION OF PROACTIVE MONITORING TOOLS FOR MEDICAL WASTE AT PHUC YEN GENERAL HOSPITAL AND} THANH HOA GENERAL HOSPTAL IN 2017

Objectives: To evaluate on the effectiveness of applying proactive environmental monitoring tools for medical solid waste sorting, collection and transportation at Phuc Yen regional general hospital and Thanh Hoa general hospital in 2017. Methods: Intervention study, evaluated before and after intervention without a control group, at 33 hospital wards of two hospital. Results: The result show that the rate of achieving the criteria for evaluation of 